\title{
国国pubvet
}

https://doi.org/10.31533/pubvet.v16n01a1018.1-9

\section{Perfil clínico de caninos positivos para cinomose}

\author{
Carollina Mariga $^{1 * \theta}$, Cinthia Melazzo De Andrade ${ }^{2 \theta}$, Alexandre Krause ${ }^{2 \theta}$, Saulo Tadeu Lemos Pinto Filho ${ }^{2 \theta}$ \\ ${ }^{I}$ Graduanda de Medicina Veterinária na Universidade Federal de Santa Maria. Santa Maria - RS Brasil. \\ ${ }^{2}$ Professor da Universidade Federal de Santa Maria, Departamento de Clínica e Cirurgia de Pequenos Animais. Santa Maria-RS Brasil. \\ *Autor para correspondência, carollina.mariga@hotmail.com
}

\begin{abstract}
Resumo. Este estudo teve como objetivo classificar o perfil clínico dos cães acometidos por cinomose no Hospital Veterinário Universitário de uma Instituição de Ensino Superior (IES) do Rio Grande do Sul. Para isso, foram revisados os históricos clínicos dos animais atendidos no hospital no período de janeiro de 2017 a julho de 2019, por meio dos prontuários dos pacientes. Neste período, 365 animais foram suspeitos para a doença. A prevalência da doença foi de 11,5\% (42/365). Os pacientes positivos foram classificados conforme raça, gênero, idade, estado de vacinação e, então, separados de acordo com os sistemas envolvidos: digestório, neuromuscular, multissistêmico, hematopoiético, respiratório, linfático, oftálmico, urinário e tegumentar; sinais clínicos e a presença de doenças concomitantes. A cinomose acomete mais animais sem raça definida e com menos de um ano de idade, entretanto, não apresenta predisposição de gênero. Foi observado que a maioria dos cães não havia histórico de vacinação prévio. O presente estudo visa salientar a importância dessas infecções virais, que acometem principalmente animais jovens sem vacinação, reforçando que medidas de prevenção se tornam imprescindíveis para seu controle e melhor estado sanitário da população canina.
\end{abstract}

Palavras-chave: Cinomose, prevalência, sinais clínicos, sistemas

\section{Clinical profile of dogs affected by distemper disease}

\begin{abstract}
This study aimed to classify the clinical profile of dogs affected by distemper disease at the Veterinary University Hospital of a higher education institution in Rio Grande do Sul. The clinical histories of the animals seen at the hospital from January 2017 to July 2019 were reviewed, using the patients' medical records. During this period, 365 animals were suspected to have distemper disease. The prevalence of disease was $11,5 \%$ (42/365). Positive patients were classified according to breed, gender, age, and vaccination status, then separated according to the bodily systems involved: digestive, neuromuscular, multisystemic, hematopoietic, respiratory, lymphatic, ophthalmic, urinary and cutaneous; clinical signs and the presence of concomitant diseases. Distemper disease affects animals of mixed breed and younger than one year old more frequently, however, it has no predisposition for gender. The researchers observed that most dogs had no previous vaccination history. This study highlights the infection patterns of this viral disease, which mainly affects young unvaccinated animals, reinforcing the notion that preventive measures are essential for his control and the protection of the health of canine populations.
\end{abstract}

Key words: Clinical signs, distemper disease, prevalence, systems

\section{Introdução}

A cinomose se trata de uma enfermidade infectocontagiosa causada por Morbillivirus e de ocorrência mundial que afeta animais de diversas famílias (Mangia \& Paes, 2008; Megid et al., 2016). É a doença neurológica que mais acomete os cães (Corrêa, 1992; Freire \& Moraes, 2019; Tudury et al., 1997). Uma 
característica desta infeção é a presença de corpúsculos de inclusão eosinofílicas, também conhecidos como corpúsculos de Lentz, podendo estar presente no citoplasma ou no núcleo das células dos sistemas acometidos (Noleto et al., 2011; Schweigert et al., 2008; Silva et al., 2017). Atualmente, nos países desenvolvidos a doença se mantém controlada por meio da vacinação, embora ainda apresentem surtos esporádicos. O Brasil ainda é considerado endêmico, com grande número de mortes em decorrência da doença (Flores, 2012; Mangia \& Paes, 2008).

Segundo Portela et al. (2017), a cinomose tem prognóstico desfavorável e alta mortalidade. A cepa viral e estado imunológico do animal são fatores relevantes para estabelecer a gravidade da enfermidade. Grande parte dos animais que se recuperam dos casos agudos, permanecem com sequelas neurológicas graves. O vírus da cinomose é pantrópico, mas existem diferentes cepas, algumas mais neurotrópicas e imunossupressoras que outras (Flores, 2012; Mangia \& Paes, 2008). Segundo Portela et al. (2017) os animais acometidos geralmente não são vacinados, não receberam colostro adequadamente, houve erro no protocolo de vacinação, imunossuprimidos ou com histórico de contato com animais infectados. Cães imunossuprimidos geralmente morrem pela doença sistêmica, por meio de complicações no trato respiratório e gastrointestinal. Animais com resposta imune moderada podem manifestar sinais clínicos ou não, enquanto aqueles com boa resposta imune eliminarão o vírus sem apresentar qualquer manifestação clínica.

No município de Santa Maria, RS, mais de um quarto dos cães testados são positivos para o anticorpo contra a cinomose (Dezengrini et al., 2007). Fighera et al. (2008) afirmam que a foi a doença mais diagnosticada nas necropsias realizadas em cães adultos (de um a nove anos de idade) no Laboratório de Patologia Veterinária da Universidade Federal de Santa Maria (LPV-UFSM) e a segunda afecção em filhotes (até um ano de idade).

Conhecer o perfil clínico das doenças adaptadas à realidade de cada região é importante para que se possam estabelecer diagnósticos diferenciais frente às diversas manifestações de uma afecção, orientar o tutor na prevenção, facilitar o diagnóstico e estabelecer tratamento de forma ágil para obter maior taxa de sucesso e melhora clínica do paciente. Desta forma, o objetivo deste trabalho foi estabelecer o perfil clínico de cães positivos para cinomose atendidos no Hospital Veterinário Universitário da Universidade Federal de Santa Maria (HVU-UFSM).

\section{Material e métodos}

Foram revisados os históricos clínicos dos animais atendidos no HVU-UFSM no período de janeiro de 2017 a julho de 2019. Os cães com suspeita de cinomose foram testados para a presença qualitativa do antígeno ou anticorpo viral pelo teste imunocromatográfico rápido $\left(I D E X X^{\circledR}\right.$ ou Alere $\left.^{\circledR}\right)$. Os pacientes positivos foram classificados conforme raça, gênero, idade, estado de vacinação e, então, separados de acordo com os sistemas envolvidos (digestório, neuromuscular, multissistêmico, hematopoiético, respiratório, linfático, oftálmico, urinário, tegumentar), sinais clínicos e doenças concomitantes. Quanto à idade, os pacientes foram divididos em três grupos de acordo com a literatura: filhotes, até um ano de idade; adultos, de um a nove anos, e idosos, a partir dos dez anos de idade (Goldston \& Hoskins, 1999; Hoskins, 2008; Silva et al., 2007).

\section{Resultados}

Um total de 11.910 cães foram atendidos no HVU-UFSM, no período de janeiro de 2017 a julho de 2019. Deste universo, 365 (365/11.910 3,1\%) foram suspeitos de cinomose, e destes, 11,5\% (42/365) foram positivos no teste imunocromatográfico rápido. Os materiais utilizados para os exames foram: em líquor (26,2\% dos animais), plasma (47,6\%), soro (9,5\%), secreção ocular $(9,4 \%)$ e sangue total $(2,4 \%)$. Quanto às raças mais acometidas, 69,0\% (29/42) eram sem raça definida (SRD) e 31,0\% (13/42) eram de raça, sendo três dachshund e um representante para cada raça de yorkshire terrier, poodle, pinscher, chowchow, pastor alemão, pug, boiadeiro-australiano, labrador retriever, fox paulistinha e shih tzu. Quanto ao sexo, 52,4\% (22/42) eram fêmeas e 47,6\% (20/42), machos.

Os animais foram distribuídos de acordo com a faixa etária: filhotes com até um ano de idade: $23,8 \%$ (10/42); adultos de um ano até nove anos de idade: 64,3\% (27/42) e idosos acima de dez anos: 11,9\% (5/42) (Figura 1). Os animais adultos possuíam distribuição etária de 7 animais $(16,7 \%)$ com um ano de 
idade, 4 (9,5\%) com 2 anos, 4 (9,5\%) com 3 anos, 5 (11,9\%) com 4 anos, 3 (7,1\%) com 6 anos, $2(4,8 \%)$ com 7 e dois com 8 anos. Enquanto os idosos possuíam 2 (4,8\%) com 10 anos e $1(2,4 \%)$ representante com 11,12 e 15 anos de idade.

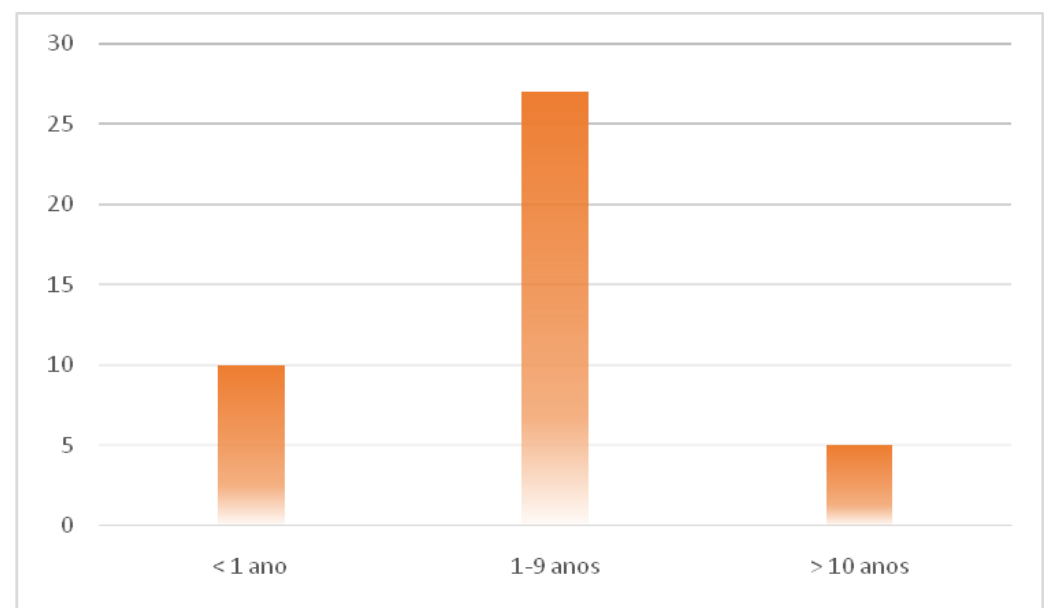

Figura 1. Distribuição etária dos animais positivos para cinomose no HVU-UFSM de janeiro de 2017 a julho de 2019 em números absolutos.

O estado sanitário revelou que $5(11,9 \%)$ animais positivos para cinomose estavam com a vacinação em dia. Apenas um $(2,4 \%)$ filhote estava durante o protocolo de introdução à imunoprofilaxia, possuindo apenas a primeira dose, e $30(71,4 \%)$ não eram vacinados. Dois cães ainda não possuíam idade mínima (6 a 8 semanas) para entrar no programa de imunização.

O sistema neuromuscular foi o mais acometido, com uma presença de $72,2 \%$ dos casos sintomáticos (26/36) de cinomose atendidos no HVU-UFSM. Destes, os sinais clínicos mais presentes foram apatia com $25,0 \%$ (9/36) dos casos; $11,1 \%$ (4/36) apresentaram miocloniass; $11,1 \%$, convulsão e $11,1 \%$, desequilíbrio, os demais sinais clínicos que foram relatados com menor frequência estão listados na tabela 1.

Tabela 1. Prevalência dos sinais clínicos do sistema neuromuscular dos animais positivos para cinomose de janeiro 2017 a julho de 2019

\begin{tabular}{lcc}
\hline Sinal clínico & Número absoluto (x/36) & Número relativo $(\%)$ \\
\hline Apatia & 9 & 25,0 \\
Mioclonias & 4 & 11,1 \\
Convulsão & 4 & 11,1 \\
Desequilíbrio & 4 & 11,1 \\
Desorientação & 3 & 8,3 \\
Fraqueza & 3 & 8,3 \\
Paraparesia & 3 & 8,3 \\
Alteração neurológica multifocal & 2 & 5,5 \\
Alteração da propriocepção & 2 & 5,5 \\
Andar em círculo & 2 & 5,5 \\
Ataxia & 2 & 5,5 \\
Nistagmo & 2 & 5,5 \\
Paraplegia & 2 & 5,5 \\
Tetraparesia & 2 & 5,5 \\
Andar a esmo & 1 & 2,8 \\
Claudicação & 1 & 2,8 \\
Dor profunda & 1 & 2,8 \\
Espasmos na cabeça & 1 & 2,8 \\
Inclinação da cabeça & 1 & 2,8 \\
Paralisia dos membros pélvicos & 1 & 2,8 \\
Paraparesia deambulatória & 1 & 2,8 \\
Paresia dos membros torácicos & 1 & 2,8
\end{tabular}

O segundo sistema mais acometido foi o digestório, presente em 63,9\% (23/36) dos casos clínicos. Os sinais clínicos de maior prevalência foram a diarreia e anorexia, ambas com 27,8\% (10/36), o restante dos sinais clínicos estão listados na tabela 2. 
Tabela 2. Prevalência dos sinais clínicos do sistema digestório dos animais positivos para cinomose de janeiro 2017 a julho de 2019

\begin{tabular}{lcc}
\hline Sinal clínico & Número absoluto (x/36) & Número relativo $(\%)$ \\
\hline Anorexia & 10 & 27,8 \\
Diarreia & 10 & 27,8 \\
Emagrecimento & 4 & 11,1 \\
Hiporexia & 4 & 11,1 \\
Desidratação & 3 & 8,3 \\
Emese & 3 & 8,3 \\
Sialorreia & 2 & 5,5 \\
Constipação & 1 & 2,8 \\
\hline
\end{tabular}

Os sinais oftálmicos ocorreram em 50,0\% (18/36) dos pacientes, sendo o sinal clínico de maior prevalência a secreção ocular presente em todos os casos. Logo após vieram os sistemas respiratório $38,9 \%$ (14/36) com secreção nasal em 25,0\% (9/36) dos casos e tegumentar 19,4\% (7/36) com hiperqueratose em 8,3\% (3/36) dos pacientes. Os demais sinais clínicos dos sistemas anteriores e os demais sistemas e respectivos sinais clínicos relatados estão listados na tabela 3 . Considerando o acometimento multissistêmico em 19,4\% (7/36), urinário em 5,5\% (2/36) e linfático em 2,8\% (1/36) dos casos.

Tabela 3. Prevalência dos demais sistemas e sinais clínicos relacionados aos animais positivos para cinomose de janeiro de 2017 a julho de 2019

\begin{tabular}{llcc}
\hline Sistema & Sinal Clínico & $\begin{array}{c}\text { Número absoluto } \\
(\mathrm{x} / 36)\end{array}$ & $\begin{array}{c}\text { Número relativo } \\
(\%)\end{array}$ \\
\hline Oftálmico & Secreção ocular & 18 & 50,0 \\
& Conjuntivite & 2 & 5,5 \\
& Úlcera de córnea & 1 & 2,8 \\
\hline Respiratório & Secreção nasal & 9 & 25,0 \\
& Tosse & 7 & 19,7 \\
& Taquipneia & 4 & 11,1 \\
& Espirros & 2 & 5,5 \\
\hline Tegumentar & Hiperqueratose & 3 & 8,3 \\
& Hipotriquia próximo aos olhos & 2 & 5,5 \\
& Pústulas abdominais & 2 & 5,5 \\
& Seborreia & 2 & 5,5 \\
& Crescimento exacerbado das unhas & 1 & 2,8 \\
& Descamação & 1 & 2,8 \\
& Enfisema subcutâneo & 1 & 2,8 \\
& Lesão lacerada cervical & 1 & 2,8 \\
& Perda de pelos & 1 & 2,8 \\
\hline Multissistêmico & Hipertermia & 6 & 16,7 \\
& Hipoglicemia & 1 & 2,8 \\
& Icterícia & 1 & 2,8 \\
\hline Urinário & Incontinência urinária & 2 & 5,5 \\
\hline Linfático & Linfadenomegalia & 1 & 2,8 \\
\hline
\end{tabular}

O linfonodo acometido no único paciente com linfadenomegalia foi o mandibular. Cinco $(13,8 \%)$ animais foram submetidos à eutanásia e um $(2,8 \%)$ foi a óbito durante o atendimento. As doenças concomitantes à cinomose foram: um representante com pneumonia e um com conjuntivite. Os diagnósticos anteriores incluíram um cão com histórico de doença renal crônica, um com pneumonia e um com espondilose anquilosante.

Os sinais clínicos diferem de acordo com a faixa etária, para os filhotes tiveram prevalência de secreção ocular 8/9 (88,9\%), seguido de diarreia 4/9 (44,4\%) e hipertermia 3/9 (33,3\%); os adultos apresentaram apatia 8/23 (34,8\%), secreção ocular 7/23 (30,4\%) e anorexia 6/23 (26,1\%); enquanto os idosos apresentaram apatia, hiporexia, secreção ocular e anorexia como principais sinais clínicos presentes em $2 / 4(50 \%)$ dos casos.

Em 32 cães o hemograma foi realizado. 21/32 (65,6\%) apresentaram anemia, sendo $13(61,9 \%)$ classificadas como anemia normocítica normocrômica, 4 (19,1\%) normocítica hipocrômica, $2(9,5 \%)$ anemia macrocítica hipocrômica e $2(9,5 \%)$ anemia microcítica normocrômica. Oito $(25,0 \%)$ animais tiveram níveis baixos de proteínas plasmáticas. A trombocitopenia esteve presente em $19(59,4 \%)$ dos pacientes, sendo que em dois deles observou-se macroplaquetas. Metarrubrícitos estavam presentes em 
cinco $(15,6 \%)$ cães. O leucograma demonstrou leucopenia em $5(15,6 \%)$ exames, sendo que o perfil de células foram $26(81,2 \%)$ com linfopenia, $7(21,9 \%)$ com eosinopenia, $3(9,4 \%)$ com neutropenia e 2 $(6,4 \%)$ com monocitopenia. Leucocitose em $3(9,4 \%)$ pacientes, sendo $6(18,7 \%)$ por neutrofilia e 3 $(9,4 \%)$ por monocitose. Bastonetes foram encontrados em $8(25,0 \%)$ animais, sendo que quatro $(50,0 \%)$ deles manifestaram aumento deste tipo celular. O corpúsculo de Lentz esteve presente em 6 dos 32 $(18,7 \%)$ caninos que possuíam exame de sangue realizado.

Vinte e quatro cães tinham exames bioquímicos anexados ao histórico, sendo as alterações mais marcantes: 8/24 (33,3\%) apresentaram hipoalbuminemia, $6(25,0 \%)$ tiveram aumento na atividade da ALT (alanina aminotransferase), $12(50,0 \%)$ aumento na atividade da FA (fosfatase alcalina), em 6 $(25,0 \%)$ foi possível observar baixa concentração de ureia enquanto $4(16,7 \%)$ tinham ureia acima dos valores de referência para a espécie.

\section{Discussão}

Apesar da cinomose se apresentar de várias formas inespecíficas, o acometimento neurológico multifocal associado à hipertermia, alterações respiratórias, diarreia, secreção ocular, hiperqueratose, mioclonias e histórico de não vacinação são indicativos de cinomose (Tudury et al., 1997). O presente estudo corrobora o seu caráter multissistêmico em cães. Os participantes apresentaram manifestações clínicas compatíveis com a doença, embora 25 a 75\% dos acometidos não sejam sintomáticos (Garde et al., 2013).

O presente estudo detectou níveis menores de positividade (11,5\%) à cinomose se comparado à soroprevalência no ano de 2007 em Santa Maria/RS que relatou 27,3\% (Dezengrini et al., 2007). Apesar da alta especificidade e sensibilidade do teste utilizado, há possibilidade de resultados falsos, com isso, outros métodos de diagnóstico devem ser realizados frente a resultados questionáveis.

De acordo com Sonne et al. (2009) foram 44,4\% animais SRD e 66,6\% de raças definidas, sendo elas: Poodle, Dachshund e Rottweiler as mais prevalentes em ordem decrescente. Schumaker et al. (2012) mostraram uma prevalência das raças Chihuahua e Dachshund (16,7\%) entre as múltiplas raças relatadas. No estudo atual, houve maior proporção de animais SRD acometidos por cinomose $(69,0 \%)$, concordando com Budaszewski et al. (2014). Destaca-se que a grande maioria dos animais atendidos no HVU são sem raça definida e é possível que a maior quantidade de casos positivos aconteça nestes cães por este motivo, e não por predisposição. Entre os cães de raça, o Dachshund foi a mais prevalente neste trabalho, o que também foi encontrado por Sonne et al. (2009) no que diz respeito à importância da doença para esta raça.

O presente estudo relata maior acometimento nas fêmeas, diferente do que foi encontrado por Sonne et al. (2009) que tiveram maior prevalência em machos que em fêmeas, sendo 59,26\% e 40,74\%, respectivamente. Em contrapartida, Sonne et al. (2009) ressaltam que a diferença nos quesitos raça e gênero não comprovaram predisposição de acometimento da doença, enquanto outros autores consideram como fator de risco devido à diferença comportamental entre os gêneros (Dezengrini et al. 2007).

Segundo Silva et al. (2007), a cinomose pode acometer cães de qualquer idade, raça e gênero, com maior incidência em filhotes, já no presente estudo, houve prevalência em animais adultos jovens, principalmente entre um e cinco anos. Considera-se que a metodologia de classificação etária utilizada na bibliografia e este artigo sejam diferentes, não seguindo a mesma faixa etária para os diferentes grupos. Esta oposição também pode ser justificada pela falta de reforço da vacinação ao longo da vida dos animais adultos, considerando que nesta pesquisa 71,4\% (30/42) dos animais do levantamento não possuíam vacinação em dia, destes, 52,4\% (22/42) eram adultos, enquanto apenas 19,0\% (8/42) eram filhotes. Também é importante ser levado em consideração que filhotes possuem a janela imunológica durante o processo de vacinação e uma idade mínima ( 6 a 8 semanas de idade) para início do programa de vacinação.

Segundo Flores (2012), cães com cinomose apresentam secreção nasal e ocular, pústulas abdominais, hiperqueratose dos coxins e plano nasal, complicações como pneumonia por infeções bacterianas secundárias, diarreia, encefalite e desmielinização do sistema nervoso central (SNC), mioclonias, hiper salivação, tremores musculares e incoordenação motora. Nosso levantamento apresenta os mesmos sinais clínicos descritos pelos autores acima. No entanto, difere em parte com a prevalência de 
manifestações encontradas por Silva et al. (2007), onde os sinais clínicos neurológicos mais presentes foram: mioclonias $(38,4 \%)$, ataxia $(25,0 \%)$, convulsões $(18,5 \%)$ e paraplegia $(13,4 \%)$, entretanto, neste levantamento foram: apatia $(25,0 \%)$, mioclonias $(11,1 \%)$, convulsão $(11,1 \%)$ e desequilíbrio $(11,1 \%)$, considerando que são estudos realizados no mesmo hospital veterinário, porém em épocas e casuísticas diferentes. Salienta-se a distinção de parâmetros clínicos utilizados pelos artigos citados e do presente artigo.

Metade dos animais do nosso estudo tiveram acometimento oftálmico, todos com secreção ocular e alguns combinados à conjuntivite ou úlcera de córnea. Enquanto Budaszewski et al. (2014) apresentam menor prevalência de secreção ocular. Segundo Gelatt (2003), a cinomose é uma das causas frequentes de conjuntivite que rapidamente evolui para a presença de secreção purulenta devido a infecções bacterianas secundárias, por vezes, evolui para conjuntivite seca devido à toxicidade viral sobre a glândula lacrimal, acarretando, muitas vezes, em doença da córnea progressiva.

Nosso levantamento mostra que o sistema digestório foi o segundo mais acometido, principalmente na forma de anorexia e diarreia, sucedido por disbiose intestinal e possíveis infecções oportunistas. Budaszewski et al. (2014) relataram 65,5\% de gastroenterite nos cães com cinomose, sendo 39,9\% com hematoquezia. Ainda salientam que 45,5\% dos animais apresentavam apenas sinais gastrointestinais. Mesmo que o vírus seja eliminado de alguns órgãos e do sangue periférico, pode permanecer na úvea, sistema nervoso central, órgãos linfoides e nos coxins (Rendon-Marin et al., 2019).

A prevalência de sinais clínicos de acordo com a faixa etária difere, sendo para os filhotes primeiramente, secreção ocular 8/9 (88,9\%), seguido de diarreia 4/9 $(44,4 \%)$ e hipertermia 3/9 $(33,3 \%)$. Os adultos apresentaram apatia 8/23 (34,8\%), secreção ocular 7/23 (30,4\%) e anorexia 6/23 (26,1\%). Os idosos apresentaram apatia, hiporexia, secreção ocular e anorexia como principais sinais clínicos presentes em 2/4 (50\%) dos casos. Até o conhecimento dos autores não foram encontrados trabalhos dividindo sinais clínicos de cinomose pela a faixa etária e até onde se tem conhecimento, os sinais clínicos devem ser os mesmos independentemente da idade do paciente.

Mais de $65 \%$ dos animais apresentaram anemia, dado semelhante aos descritos por outros autores (Almeida et al., 2009; Barbosa et al., 2011). O perfil predominante da anemia foi normocítica (80,9\%) normocrômica $(71,4 \%)$, assim como os achados de Almeida et al. (2009), enquanto as descritas por Tudury et al. (1997) foram, principalmente, microcítica $(64,86 \%)$ e hipocrômica $(72,97 \%)$. Almeida et al. (2009) explicam que após a infecção e multiplicação do vírus, há o envolvimento da medula óssea e consequente rota de infecção para outras células circulantes, como leucócitos e eritrócitos. Desta forma, a anemia pode ser resultado da destruição das células pela presença do vírus nos eritrócitos ou pela deposição de imunocomplexos na membrana dos mesmos (Headley et al., 2012).

Segundo Tudury et al. (1997), as principais alterações do leucograma foram leucocitose, neutrofilia e linfopenia. Já neste estudo as principais alterações foram linfopenia (81,2\%), eosinopenia $(21,9 \%)$ e neutrofilia (18,7\%). Entretanto, Almeida et al. (2009) não registrou alteração na contagem de leucócitos e neutrófilos. Barbosa et al. (2011) relataram prevalência semelhante na linfopenia, sendo a alteração mais significativa do leucograma. A linfopenia é esperada em quadros de cinomose pelo tropismo, atrofia e necrose do tecido linfoide produzida pela ação do vírus, assim como a leucocitose é esperada em infecções bacterianas oportunistas (Jain \& Jain, 1993; Silva et al., 2017). Segundo Silva et al. (2017), as alterações no leucograma mais importantes foram leucopenia $(22,6 \%)$ e leucocitose $(13,2 \%)$, em comparação com o atual estudo, que obteve apenas $15,6 \%$ e $9,4 \%$, respectivamente.

Segundo Silva et al. (2017) a baixa taxa de corpúsculos de Lentz encontrada neste estudo (18,7\%) pode ser explicada que sua presença se dá durante o curto período de viremia da doença. Portanto, não são encontrados facilmente na rotina hematológica. Tudury et al. (1997) obteve oscilação entre 30 e $45 \%$ da presença de corpúsculos de Lentz em diferentes órgãos utilizados para o diagnóstico em seu estudo, enquanto Vicente et al. (2010) encontraram em 86,7\% dos animais acometidos.

A hipoalbuminemia, encontrada em cinco animais, pode estar relacionada com déficit alimentar, principalmente de fontes proteicas, parasitismo gastrointestinal subdiagnosticado e doença renal, sendo que três $(12,5 \%)$ animais apresentaram anormalidades compatíveis (González \& Scheffer, 2002). Segundo Silva et al. (2015) relataram que 51,4\% apresentaram hipoalbuminemia, enquanto $80 \%$ e $70 \%$ 
dos casos apresentaram níveis normais para ALT e ureia, respectivamente. Kaneko et al. (2008) não atribuem essas alterações à cinomose.

Segundo Fighera et al. (2008), nos animais necropsiados na mesorregião centro ocidental do Rio Grande do Sul, 35,0\% apresentaram algum tipo de doença infecciosa ou parasitária relacionados à baixa adesão aos programas de vacinação. A distribuição de acometimento dentre as faixas etárias foram: filhotes com 55,3\%, adultos $27,5 \%$ e idosos $12,4 \%$. A atual pesquisa revelou positividade para cinomose de $11,5 \%$ e a distribuição etária com maior prevalência foi em adultos $(64,2 \%)$, filhotes com $23,8 \%$ e idosos, $11,9 \%$ dos casos. Filhotes são mais suscetíveis às doenças pela questão imunitária (Silva et al., 2009), assim como a combinação de fatores de ausência da vacinação, exposição ao patógeno em não vacinados após perda de imunidade materna/passiva (também chamada de janela de suscetibilidade) e baixa concentração de anticorpos por via materna. Filhotes são mais suscetíveis a patógenos, o que justifica maior acometimento por cinomose neste período da vida (Greene \& Vandevelde, 2015; Ramsey \& Tennant, 2010). Este artigo é baseado em resultados realizados apenas por imunocromatografia, enquanto o estudo realizado por Fighera et al. (2008) foi com achados histopatológicos. Como as metodologias foram distintas, entende-se que há diferentes níveis de sensibilidade e especificidade entre os testes utilizados em ambas as pesquisas.

Segundo Silva et al. (2007), os filhotes são menos afetados por distúrbios neurológicos por desenvolverem imunidade parcial ao patógeno, sendo assim, se a doença ocorrer durante a fase adulta, haverá maior chance de aparecimento de sinais neurológicos. Os casos neurológicos ocorreram 45,9\% em filhotes, $51,4 \%$ em adultos e 2,7\% em idosos. Entretanto, os sinais clínicos neurológicos citados neste artigo estiveram presentes em 50,0\% (2/4) dos idosos, 55,5\% (5/9) dos filhotes, enquanto 78,3\% (18/23) dos adultos foram acometidos, sendo que o sinal clínico neurológico mais presente em adultos e idosos foi apatia.

A imunoprofilaxia é o principal fator na prevenção da cinomose. Tudury et al. (1997) observaram que 70,4\% dos cães avaliados com sinais sistêmicos e neurológicos suspeitos de cinomose nunca haviam sido imunizados, $11,1 \%$ possuíam uma dose da vacina e $18,5 \%$ estavam em dia de acordo com o protocolo. $\mathrm{O}$ presente estudo possui uma porcentagem semelhante com relação aos animais não vacinados $(71,4 \%)$, enquanto apenas um $(2,4 \%)$ estava durante o período de imunoprofilaxia e apenas cinco $(11,9 \%)$ estavam em dia. $14,3 \%$ dos pacientes não possuíam esse tipo de informação no seu histórico. Protocolos adequados onde todos os filhotes devem receber as vacinas da cinomose entre a 6 e 16 semanas de vida, com reforço a cada três a quatro semanas. É necessário reforço após um ano da primovacinação e, então, somente a cada três anos (Megid et al., 2016; Ramsey \& Tennant, 2010). Day et al. (2020) reforçam que a revacinação seja realizada apenas a cada três anos, explicando que maior frequência não irá aumentar o grau de proteção, mas que pode aumentar o risco de reações adversas à vacina. Ressaltam que é mais importante assegurar a imunidade de rebanho em geral, com exceção aos animais de risco, como os animais errantes, para revacinações anuais.

\section{Conclusão}

Os resultados deste estudo permitem concluir que a prevalência da cinomose canina no HVU-UFSM é de $11,5 \%$ de positividade. O perfil clínico apresenta predisposição para animais sem raça definida e adultos, seguido pelos jovens. O estado sanitário é de $71 \%$ animais não vacinados, o que ressalta a importância da imunização em massa contra esta enfermidade para diminuir a sua prevalência na região de Santa Maria - RS. O sistema mais acometido foi o neuromuscular, seguido pelo digestório e oftálmico.

Conflito de interesses: Os autores declaram não haver conflito de interesse.

\section{Referências bibliográficas}

Almeida, R. K., Vasconcelos, A. C., Carneiro, R. A., Paes, P. R., \& Moro, L. (2009). Alterações citológicas do sangue periférico e da medula óssea de cães com cinomose. Arquivo Brasileiro de Medicina Veterinária e Zootecnia, 61, 1255-1260. 
Barbosa, T. de S., Vieira, R. F. C., Viol, M. A., Soeiro, C. S., Bomfim, S. R. M., \& Ciarlini, P. C. (2011). Avaliação laboratorial da cinomose canina: estudo retrospectivo de 25 casos no município de Araçatuba-SP. Revista de Ciências Agroveterinárias, 10, 113-118.

Budaszewski, R. F., Pinto, L. D., Weber, M. N., Caldart, E. T., Alves, C. D. B. T., Martella, V., Ikuta, N., Lunge, V. R., \& Canal, C. W. (2014). Genotyping of canine distemper virus strains circulating in Brazil from 2008 to 2012. Virus Research, 180, 76-83. https://doi.org/10.1016/j.virusres.2013.12.024.

Corrêa, W. M. (1992). Cinomose. In W. M. Corrêa \& C. N. M. Corrêa (Eds.), Enfermidades infecciosas dos mamíferos domésticos (pp. 655-670). Medsi.

Day, M. J., Crawford, C., Marcondes, M., \& Squires, R. A. (2020). Recomendações sobre a vacinação para médicos veterinários de pequenos animais da América Latina: um relatório do Grupo de Diretrizes de Vacinação da WSAVA. Journal of Small Animal Practice, 1-39.

Dezengrini, R., Weiblen, R., \& Flores, E. F. (2007). Soroprevalência das infecções por parvovírus, adenovírus, coronavírus canino e pelo vírus da cinomose em cães de Santa Maria, Rio Grande do Sul, Brasil. Ciência Rural, 37(1), 183-189.

Fighera, R. A., Souza, T. M., Silva, M. C., Brum, J. S., Graça, D. L., Kommers, G. D., Irigoyen, L. F., \& Barros, C. S. L. (2008). Causas de morte e razões para eutanásia de cães da Mesorregião do Centro Ocidental Rio-Grandense (1965-2004). Pesquisa Veterinária Brasileira, 28(4), 223-230. https://doi.org/10.1590/s0100-736x2008000400005.

Flores, E. F. (2012). Virologia veterinária. Universidade Federal de Santa Maria.

Freire, C. G. V., \& Moraes, M. E. (2019). Cinomose canina: aspectos relacionados ao diagnóstico, tratamento e vacinação. PUBVET, 13(2), 1-8.

Garde, E., Pérez, G., Acosta-Jamett, G., \& Bronsvoort, B. (2013). Characteristics of a canine distemper virus outbreak in Dichato, Chile following the February 2010 earthquake. Animals, 3(3), 843-854.

Gelatt, K. N. (2003). Manual de oftalmologia veterinária. Editora Monole.

Goldston, R. T., \& Hoskins, J. D. (1999). Geriatria e gerontologia do cão e do gato. Rocca.

González, F. H. D., \& Scheffer, J. F. S. (2002). Perfil sanguíneo: ferramenta de análise clínica, metabólica e nutricional. In F. H. D. González (Ed.), Avaliação metabólico-nutricional de vacas leiteiras por meio de fluídos corporais (sangue, leite e urina) (pp. 5-17). Arquivos do $29^{\circ}$ Congresso Nacional de Medicina Veterinária, Gramado, RS.

Greene, C. E., \& Vandevelde, M. (2015). Cinomose. In C. E. Greene (Ed.), Doenças infecciosas em cães e gatos. Guanabara Koogan.

Headley, S. A., Amude, A. M., Alfieri, A. F., Bracarense, A. P., \& Alfieri, A. A. (2012). Epidemiological features and the neuropathological manifestations of canine distemper virus-induced infections in Brazil: a review. Semina: Ciências Agrárias, 33(5), 1945-1978.

Hoskins, J. D. (2008). Geriatria e Gerontologia do cão e do gato. Editora Roca.

Jain, N. C., \& Jain, A. H. (1993). Essentials of Veterinary Hematology (1 st ed.). Wiley-Blackwell.

Kaneko, J. J., Harvey, J. W., \& Bruss, M. L. (2008). Clinical biochemistry of domestic animals (6th ed. (ed.); Vol. 1). Academic press.

Mangia, S. H., \& Paes, A. C. (2008). Neuropatologia da cinomose. Veterinária e Zootecnia, 15(3), 416427.

Megid, J., Ribeiro, M. G., \& Paes, A. C. (2016). Doenças infecciosas em animais de produção e de companhia. Roca.

Noleto, P. G., Mendonça, C. S., Fernandes, C. C., Mantovani, M. M., Tsuruta, S. A., Sola, M. C., \& Mundim, A. V. (2011). Corpúsculos de Lentz em um cão com 10 dias de idade. Bioscience Journal, 27(1), 112-115.

Portela, V. A. B., Lima, T. M., \& Maia, R. C. C. (2017). Cinomose canina: revisão de literatura. Medicina Veterinária (UFRPE), 11(3), 162-171.

Ramsey, I. K., \& Tennant, J. R. B. (2010). Manual de doenças infecciosas em cães e gatos. São Paulo: Roca. 
Rendon-Marin, S., Budaszewski, R. F., Canal, C. W., \& Ruiz-Saenz, J. (2019). Tropism and molecular pathogenesis of canine distemper virus. Virology Journal, 16(1), 1-15. https://doi.org/10.1186/s12985-019-1136-6.

Schumaker, B. A., Miller, M. M., Grosdidier, P., Cavender, J. L., Montgomery, D. L., Cornish, T. E., Farr, R. M., Driscoll, M., Maness, L. J., \& Gray, T. (2012). Canine distemper outbreak in pet store puppies linked to a high-volume dog breeder. Journal of Veterinary Diagnostic Investigation, 24(6), 1094-1098. https://doi.org/10.1177/1040638712460531.

Schweigert, A., Cavalheri, W. M., Fernandes, R. F., \& Gebara, C. M. S. (2008). Frequência de corpúsculos de inclusão de Lentz em células sanguíneas e oculares de cães suspeitos de cinomose atendidos no Hospital Veterinário da faculdade integrado de Campo Mourão-PR. Campo Digital, 3(1), 90-92.

Silva, G. A., Araújo, E. K. D., Leite, A. G. P. M., Alencar, D. F., Prado, A. C., Oliveira, W. A., \& Cardoso, J. F. S. (2017). Parâmetros hematológicos de cães apresentando corpúsculos de Lentz em esfregaço sanguíneo. PUBVET, 11(10), 1022-1027. https://doi.org/10.22256/pubvet.v11n10.10221027.

Silva, J. H., Minchuerri, L. S., \& Kolber, M. (2015). Levantamento dos aspectos clínicos e laboratóriais no diagnóstico de cinomose canina do hospital veterinário da Universidade Metodista de 2013 a 2015. Revista Científica Eletrônica de Medicina e Veterinária, 1-11.

Silva, M C, Fighera, R. A., Juliana, S., Graça, D. L., Kommers, G. D., Irigoyen, L. F., \& Barros, C. S. L. (2007). Aspectos clinicopatológicos de 620 casos neurológicos de cinomose em cães: Clinicopathological features in 620 neurological cases of canine distemper. Pesquisa Veterinária Brasileira, 27(5), 215-220.

Silva, Marcia C, Fighera, R. A., Mazzanti, A., Brum, J. S., Pierezan, F., \& Barros, C. S. L. (2009). Neuropatologia da cinomose canina: 70 casos (2005-2008). Pesquisa Veterinária Brasileira, 29(8), 643-652.

Sonne, L., Oliveira, E. C., Pescador, C. A., Santos, A. S., Pavarini, S. P., Carissimi, A. S., \& Driemeier, D. (2009). Achados patológicos e imuno-histoquímicos em cães infectados naturalmente pelo vírus da cinomose canina. Pesquisa Veterinária Brasileira, 29, 143-149. https://doi.org/10.1590/S0100736X2009000200010.

Tudury, E. A., Arias, M. V. B., Bracarense, A. P. F. L., Megid, J., \& Dias Júnior, R. F. (1997). Observações clínicas e laboratoriais em cães com cinomose nervosa. Ciência Rural, 27(2), 229-235.

Vicente, A. F., Abreu, A. P. M., \& Passos, A. A. M. S. (2010). Perfil hematológico em cães infectados naturalmente por Cinomose com presença de corpúsculo de Sinegaglia Lentz, em Vassouras-RJ. Revista de Saúde, 1(1), 49-54.

\section{Histórico do artigo:}

Recebido: 14 de setembro de 2021

Aprovado: 13 de outubro de 2021

Disponível online: 3 de janeiro de 2022
Licenciamento: Este artigo é publicado na modalidade Acesso Aberto sob a licença Creative Commons Atribuição 4.0 (CC-BY 4.0), a qual permite uso irrestrito, distribuição, reprodução em qualquer meio, desde que o autor e a fonte sejam devidamente creditados. 